\title{
A Percepção de Si como Sujeito-da-Doença*
}

REGINA HERZOG**

É em fins do século XIX que se pode situar o nascimento da medicina moderna, pela gradativa valorização do saber médico enquanto "uma estratégia biopolítica". Segundo Foucault, com o advento do capitalismo a medicina ganha novo estatuto, na medida em que o corpo passa a ser visto como força de produção. Tal ascensão, entretanto, foi paulatina, começando como uma medicina do Estado (início do século XVIII), principalmente na Alemanha, onde o Estado se configura como objeto de conhecimento e lugar onde se produz conhecimento; a seguir, passa por uma "medicina das condições de vida, do meio de existência"1 que the confere um estatuto de ciência, até chegar, finalmente, a uma medicina da força de trabalho, que realiza um controle mais completo dos indivíduos, pela assistência e intervenção médicas.

* Texto extraído do capítulo IV de "Sujeito-da-doença ou doença do sujeito? A construção do ser doente". Dissertação de mestrado em psicologia clínica, apresentada à PUC-RJ. Novembro de 1987.

** Doutoranda em Psicologia, PUC/RJ.

1 FOUCAULT M., "Conferências (6) realizadas na Universidade do Estado do Rio de Janeiro." Mimeo, 1974, p. 17. 
Nessa perspectiva, a análise de Michel Foucault ${ }^{2}$ permite entrever como o saber médico respalda um controle mais refinado do indivíduo na nova racionalidade política que se configura a partir do século XIX, tendo como objetivo maior a sujeição do ser humano.

Instituída como saber, a medicina, por seu discurso, dá uma configuração concreta à sua prática, constituindo um sujeito-da-doença ${ }^{3}$ que, por sua vez, assegura a hegemonia do saber médico.

A expressão sujeito-da-doença reflete, segundo nosso ponto de vista, uma intenção subjacente à constituição da medicina moderna - a do exercício de um poder sobre o corpo, lugar onde acontece a doença. Nesta perspectiva, é para a doença que o saber médico precisa propor um atributo, e não para 0 indivíduo. Assim, destituindo o lugar em que ocorre a doença de um significado que possa transcendê-la para além da construção de um sujeito-da-doença, o que se institui é a idéia de que todo indivíduo, ou seja, todo sujeito é passível de ser sujeito-da-doença.

Feita essa ressalva, a análise empreendida por Foucault, principalmente em $O$ nascimento da clínica, ${ }^{4}$ reafirma suas idéias sobre como o sujeito é constituído pelas práticas discursivas. Não obstante, esta caracterização não desconsidera que a construção do saber médico de um sujeito-da-doença construção esta que, em última análise, instaura uma relação de poder - não deve ser entendida como um movimento unilateral, no qual um dos pólos é criador/dominante e outro criação/dominado. A este respeito, Foucault aponta para as formas de submissão engendradas pelo próprio sujeito. ${ }^{5}$

O objetivo desta reflexão é discutir como, a partir do discurso médico, o sujeito se percebe como passível de ser sujeito-da-doença e/ou sujeito-dedoença. Para pensar essa questão, pretendo buscar na análise de Foucault subsídios sobre os diversos tipos de poder que tornam os seres humanos sujeitos.

Com esse objetivo será delineado, num primeiro momento, o que entendo como as raízes sociais da percepção de si como sujeito. Em seguida, tomando o ponto de vista do sujeito, será analisado como, a partir de um sentir-se mal,

2 FOUCAULT M., O nascimento da clínica. Rio de Janeiro, Forense-Universitária, 1980, p. XVIII.

3 HERZOG R., "Sujeito-da-doença ou doença do sujeito? A construção do ser doente", op. cit.

4 FOUCAULT M., $O$ nascimento da clínica, op. cit.

5 FOUCAULT M., "Deux essais sur le sujet et le pouvoir", in DREYFUS H.L. \& RABINOW P., Michel Foucault: un parcours philosophique. Paris, Gallimard, 1984. 
se passa da percepção de sujeito passível de ser sujeito-da-doença para a de sujeito-da-doença, através de uma sequiência: "estou doente", "sou doente", "sou paciente".

\section{Tipos de poder que tornam os seres humanos sujeitos}

Foucault, cuja obra está voltada para "os diferentes modos de subjetivação do ser humano em nossa cultura", 6 investiga, através de várias formas de resistência, como se exercem na atividade "os diferentes tipos de poder"" que açambarcam o indivíduo como um todo, classificando-o, impondo uma lei que precisa ser aceita e, enfim, transformando-o em sujeito.

Determinando duas acepções para o termo sujeito - "sujeito submetido ao outro pelo controle e dependência e sujeito ligado à sua própria identidade pela consciência ou conhecimento de si" ${ }^{8}$ - Foucalt considera que este termo implica "uma forma de poder que subjuga e sujeita".

Para se constituir a possibilidade dessa forma de poder, Foucault propõe a existência de três tipos de objetivação que transformam os seres humanos em sujeitos.

O primeiro diz respeito aos diversos modos de investigação que pretendem a cientificidade; por exemplo, a "objetivação do sujeito falante" promovida pela filologia e outros; ou do "sujeito produtivo", pela "economia e análise das riquezas"; ou ainda, "a objetivação do proprio fato de estar vivo, em história natural ou em biologia".

Um segundo tipo é designado como pratiques divisantes, em que "o sujeito é dividido no interior de si mesmo ou em relação aos outros".

O terceiro, que Foucault se propõe a investigar em sua obra, se refere "à maneira como um ser humano se transforma em sujeito", como, por exemplo, "o sujeito de uma sexualidade".

Tomando como ponto de partida para sua investigação "as formas de resistência aos diferentes tipos de poder", ele identifica três tipos de luta possíveis: contra as formas de dominação, as de exploração e a forma que "liga o indivíduo a ele mesmo e assegura assim sua submissão às outras". ${ }^{10} \mathrm{Sem}$ negar que estas formas de luta podem ser travadas conjuntamente, considera

\footnotetext{
6 FOUCAULT M., "Deux essais sur le sujet et le pouvoir”, op. cit., p. 297.

7 Idem, p. 300.

8 Idem, p. 303.

9 Idem, p. 303.

10 Idem, p. 303.
} 
que, na atualidade, a que predomina $€$ aquela "contra a submissão da subjetividade".11

A partir da análise de uma técnica de poder - o poder pastoral -, Foucault indica como o Estado ocidental moderno passa a exercer um poder com características semelhantes àqueles nos quais o poder ordena e se sacrifica por seu rebanho/povo; se preocupa com o conjunto da comunidade, mas também com cada um separadamente; age porque sabe tudo sobre todos. Desta forma, o Estado moderno passa a exercer, sobre a saúde, uma forma de poder que abrange todos os indivíduos e o indivíduo como um todo; retoma, assim, os instrumentos com os quais o poder pastoral exerce o poder e os amplia, pois passa a ver o indivíduo sob uma nova óptica e submetido "a um conjunto de mecanismos específicos". Assim, o objetivo final é a saúde do indivíduo no mundo, e não mais após a morte, como se verificava no poder pastoral, abrangendo várias instâncias - bem-estar físico, proteção, segurança. Além disso, se produz uma ampliação do poder, que chega a ser exercido por "estruturas complexas como a medicina, que englobava ao mesmo tempo as iniciativas privadas (venda de serviços na base da economia do mercado) e certas instituições públicas como os hospitais". ${ }^{12}$

Essa estratégia, além de reforçar, amplia o exercício do poder pastoral, que na religião se atém à Igreja (instituição eclesiástica). Trata-se de uma conformação que permite que se desenvolva "um saber sobre o homem", enquanto conjunto (a população) e enquanto indivíduo.

Esta breve exposição sobre como se exerce, na atualidade, determinado tipo de poder fornece subsídios para se pensar a questão da percepção que o sujeito vai ter de si próprio como passível de ser sujeito-da-doença e/ou sujeito-de-doença. De acordo com a análise de Foucault, esta percepção deve ser apreendida dentro de uma visão que remete à própria constituição do sujeito, submetido e subjugado pelos modos de objetivação.

Dentro do escopo deste estudo é possível ver como o corpo sujeitado pela doença expressa, de uma forma concreta, uma relação de poder das mais refinadas. O corpo se configura como o ponto para o qual convergem, de um lado, o exercício de um poder que lhe é externo, e de outro, a percepção de si como sujeito - que the é interna. A relação se manifesta por um compromisso, por parte do Estado, de cuidar desse sujeito e pela propria participação, no Estado, do sujeito que, com seu corpo, produz e trabalha. Para uma compreensão do ponto de vista do sujeito, que será privilegiado nesta reflexão, é

11 Idem, p. 303.

12 Idem, p. 306. 
necessário efetuar a análise desta relação que procede em dois níveis — de um lado o que aparece como condição externa para a percepção de si como sujeito e, de outro, a articulação interna do próprio sujeito se percebendo.

\section{Raízes sociais da percepção de si como sujeito}

Com respeito à produção, à necessidade de trabalhar para garantir possibilidade de consumo, trata-se de uma situação vivida pelo sujeito como deliberação própria, interna. Neste contexto, o corpo passa a ter uma positividade sui generis. Em lugar de servir ao sujeito, passará a ser cuidado por ele, culminando no que Baudrillard ${ }^{13}$ denomina de "demagogia do corpo". Para este autor, a nova concepção de corpo 'liberado' não passa de um engodo, na medida em que é direcionada, responde à estratégia de determinados sistemas (da medicina, da religião, d̦a economia política), de acordo com seus objetivos: "a saúde, a ressurreição, a produtividade racional, a sexualidade liberada". ${ }^{14}$

Dentro desta perspectiva, pode-se entender como a imagem do corpo, enquanto significado para o sujeito, se acha perpassada pelas diversas concepções que lhe dão um sentido. Entretanto, dificilmente poder-se-ia vincular a compreensão da noção de imagem corporal a uma explicação pautada meramente nas preocupações pessoais do indivíduo com o corpo, destacadä de um conjunto mais complexo, devidamente inserida no âmbito social. A percepção da imagem corporal não se reduz a um conhecimento de si destituído de injunções externas.

Todavia, a afirmação de que o corpo simboliza tudo, ou seja, responde à estratégia de vários sistemas, deve ser matizada, pois nela se verificam pontos de fratura. Ainda que a imagem do próprio corpo seja decorrente da imagem imposta pelo sistema (pela sociedade), observa-se, em vários contextos, um "sair da linha", como se existisse algo de que a sociedade, enquanto sistema, não dá conta, algo que a extrapola. Esta questão será abordada mais adiante. No entanto, para completar este raciocínio, pode-se traçar um paralelo com o pensamento de Mary Douglas, antropóloga que trata, em sua obra, Pureza e perigo, ${ }^{15}$ dos rituais de pureza e impureza nas culturas primitivas.

Vendo no ritual a expressão de um conjunto de elementos aos quais o indivíduo está irremediavelmente ligado, a autora relata como essa configuração nãoé tão simples, pois mesmo que "o ritual formal de ocasiões públicas

13 BAUDRILLARD J., L'echange symbolique et la mort. Paris, Gallimard, 1976.

14 B AUDRILLARD J., L'echange symbolique et la mort. Paris, Gallimard, 1976, p. 177.

15 DOUGlas M., Pureza e perigo. São Paulo, Perspectiva, 1976. 
ensine um conjunto de doutrinas, [no entanto], não há razão para supor que sua mensagem seja necessariamente coerente com aquelas ensinadas em rituais privados, ou que todos os rituais públicos sejam coerentes uns com os outros, nem todos os rituais privados". ${ }^{16}$

Assim, a análise do rito deve levar em conta que "existem outras crenças que podem não ser ritualizadas e que podem obscurecer totalmente a mensagem dos ritos. As pessoas não ouvem necessariamente a seus pregadores". ${ }^{17}$

Dessa forma, mesmo do ponto de vista social, algo escapa ao controle que é exercido por um determinado sistema. Todavia, é importante deixar bem marcado que, do ponto de vista do indivíduo, as coisas não ocorrem, absolutamente, desta maneira.

Nessa perspectiva, o corpo, do ponto de vista do indivíduo, é sua propriedade, ou seja, ele se vê como agente de sua vida e decide o que, como e se quer fazer algo, segundo suas necessidades internas. Assim, o indivíduo se percebe como um corpo que produz e trabalha, mas que em última instância é utilizado para servir às suas próprias deliberações. Por outro lado, este indivíduo tem o compromisso de que o Estado vai cuidar dele.

Tendo explicitado as injunções pela percepção de seu próprio corpo, resta voltar a atenção para este outro pólo possibilitador de uma percepção de si próprio como sujeito-da-doença, ou seja, o que diz respeito ao compromisso de cuidado com a saúde. Este, garantido pelo Estado, é de tal modo envolvente que, do ponto de vista do indivíduo, é dado como natural. Afinal, desde antes de nascer já se realiza um acompanhamento médico do sujeito, no pré-natal. $\mathrm{O}$ próprio nascimento ocorre no hospital, o nome é registrado no tabelião, previnem-se doenças pela vacinação, promovem-se campanhas de higiene, prescreve-se uma alimentação sadia acrescida de vitaminas, fazem-se necrópsias de mortes não definidas. ${ }^{18}$

Nesse tipo de procedimento, dentre outros, reside o poder do Estado e a sua própria condição de possibilidade. Assim, a tentativa de uma prática de "autogestão da saúde, que consiste na exaltação simbólica do grupo e termina eventualmente num desvario de morte", ${ }^{19}$ é extremamente perigosa para 0

16 Idem.

17 Idem.

18 Sobre a medicalização da sociedade, ver, entre outros, COSTA J.F., Ordem médica e norma familiar. Rio de Janeiro, Graal, 1983; FOUCAULT M., "Conferências (6) realizadas na Universidade do Estado do Rio de Janeiro", op. cit.; ILLICH I., A expropriação da saúde: nêmesis da medicina. Rio de Janeiro, Nova Fronteira, 1975.

19 BAUDRILLARD J., L'echange symbolique et la mort, op. cit. p. 222. 
Estado ou para outras instituições como, por exemplo, a Igreja, pois retira dessas instâncias o privilégio do poder sobre o indivíduo.

Tendo como proposta a administração da morte — que "enquanto universal da condição humana só existe depois que há uma discriminação social dos mortos" 20 - o objetivo principal da nossa cultura parece ser separá-la da vida, com a promessa de "sobrevida e eternidade pelas religiões, verdade pela ciência, produtividade e acumulação pela economia". 21

Fica caracterizado, assim, o que denominei como as raízes sociais da percepção de si como sujeito e que vai permitir apontar para a categoria de sujeito passível de ser sujeito-da-doença. Instituída pelo saber/discurso médico, esta categoria encontra ressonância na óptica do próprio sujeito. Percebe-se como um corpo que é cuidado (pelo Estado) e que serve ao indivíduo para o trabalho e/ou lazer. A possibilidade deste corpo " faltar" a qualquer momento constitui uma grande ameaça. Aprisionado por um discurso científico que promete sempre a verdade e, no caso específico, algo que quase representa a imortalidade - pois "um dia eles vão descobrir a cura para esta doença" (sic) — se transforma a ameaça num desejo de "se entregar nas mãos deles" (sic).

\section{"Tornar-se doente": "estou doente" = "sou doente" = "sou paciente"}

A condição de sujeito passível de ser sujeito-da-doença se estabelece na medida em que o indivíduo é socializado nos padrões de normalidade impostos pelo saber médico. Entretanto, de seu ponto de vista, esta condição está presente na medida em que o sujeito se vê, de um lado, cuidado pelo Estado e, de outro, cuidando de si.

Importa agora mostrar como, a partir daí, decorre o "tornar-se doente", do ponto de vista do sujeito. Este "tornar-se doente" é um termo genérico que abrange as três formas, que se apresentam numa seqüência: "estou doente", "sou doente", "sou paciente". Vinculada à situação de cronicidade, esta seqüência, no que tange às doenças curáveis, toma outra forma. Neste caso, do ponto de vista do indivíduo o "tornar-se doente" é temporário: "estive muito mal, mas agora está tudo bem" (sic). Assim, num primeiro momento um "sentir-se mal" remete à afirmação "estou doente". Com a cura, a situação foi ultrapassada: "fiquei doente, mas não estou mais", logo, "não sou doente".

20 Idem, p. 221.

21 Idem, p. 225. 


\section{"Estou doente"}

A passagem da categoria de sujeito passível de ser sujeito-da-doença para sujeito-da-doença se dá, do ponto de vista do indivíduo, através de um conjunto de fatores que pode ser englobado por um "sentir-se mal". 22

É necessário deter-se nesta expressão. Do ponto de vista do indivíduo, trata-se de uma sensação que the é própria, singular, logo, referida ao seu universo privado. Entretanto, é uma sensação partilhada com seus pares. Assim, a noção "sentir-se mal" está evidentemente inserida num universo simbólico, definido aqui como "a matriz de todos os significados socialmente objetivos e subjetivamente reais. A sociedade histórica inteira e toda a biografia do indivíduo são vistas como acontecimentos que se passam dentro deste universo". ${ }^{23}$

Tratando-se, aqui, de uma sociedade complexa em que coexiste uma pluralidade de sistemas simbólicos, o "sentir-se mal" pode estar remetido a um ou vários sistemas em que o sujeito está inserido (na religião, na medicina ou em algum outro). Desta forma, conforme apontado por Figueira, ${ }^{24}$ "é possível afirmar que o habitante típico desta sociedade enfrenta períodos de indecisão e mesmo de confusão, diante da grande variedade de ideologias conflitantes, de possibilidades de Weltanschauungen alternativas que propiciam diferentes leituras da realidade, associadas a conjuntos de regras não raro mutuamente excludentes". ${ }^{25}$

Entretanto, isto não invalida a idéia de que, como correlato ao "sentir-se mal", tem-se a concepção de "estou doente". Ou seja, como sou passível de ser sujeito-da-doença, este mal-estar, fraqueza, inchação, tonturas significam que me encontro num estado traduzível por "estou doente". A ida ao médico confirma esta idéia, ainda que ao mesmo tempo se possa ir a um terreiro, fazer promessa ou alguma outra coisa. Neste sentido, parece que, pelo menos na maior parte das vezes ou dos casos, o discurso médico, enquanto um sistema simbбlico, predomina sobre os demais, conferindo "uma interpretação abrangente da vida humana". 26

22 Para uma análise mais profunda desta questão, ver BOLTANSKI L., As classes sociais e o corpo. Rio de Janeiro, Graal, 1984.

23 BERGER P.\& LUCKMANN T., A construção social da realidade. Petrópolis, Vozes, 1983, p. 132.

24 FIGUEIRA S.A., "Notas introdutórias ao estudo das terapêuticas I: Lévi-Strauss e Peter Berger", in FIGUEIRA S.A. (coord.) Sociedade e doença mental. Rio de Janeiro, Campus, 1978.

25 Idem, p. 66.

26 Idem, p. 67. 
É importante ressaltar que pode ocorrer a busca de várias outras terapêuticas, inseridas em diferentes visões de mundo e que de certa forma dividem o estatuto de eficácia com o saber médico. A despeito do que se pensa, essa busca não parece estar vinculada, necessariamente, a essa ou àquela camada social. A este respeito, o que se pode verificar é que em determinadas camadas encontra-se de forma mais visível uma diversidade de discursos que remetem aos vários sistemas simbólicos coexistentes; já em outras camadas, em função de fatores diversos, a crença em outras formas de tratamento, ou seja, a busca de outras terapêuticas, provavelmente não se mostra de forma tão clara. ${ }^{27}$

Isto faz pensar em outros motivos que levam a essa atitude. De qualquer modo, pode-se adiantar que, tendo como pano de fundo a radicalidade da morte, a busca de várias terapêuticas — ou seja, de várias interpretações para a doença — corresponde a tentativas de resolução da situação de "sentir-se mal".

Quanto à ida ao médico, sua eficácia reside, como já visto anteriormente, numa promessa de cura e/ou numa proposta de adiamento da morte, no interior de uma perspectiva eminentemente científica. Sem dúvida, o caráter científico de uma asserção goza, na atualidade, de grande força, parecendo sobrepujar outras perspectivas. O paciente compartilha de uma "crença" com os doutores, que exigem simplesmente a obediência aos seus preceitos. Dificilmente algo se compara ao poder da "verdade" científica - é mágica.

\section{"Sou doente"}

Tendo relacionado o "sentir-se mal" a "estou doente", vamos estabelecer como se verifica a transformação em "sou doente". Se, do ponto de vista médico, o que caracteriza a transformação de sujeito passível de ser sujeito-dadoença em sujeito-da-doença é a situação de diagnóstico - exames clínicos, laboratoriais e outros - , do ponto de vista do indivíduo esta passagem se verifica a partir da designação médica, de seu veredicto, da tradução do significado de "sentir-se mal" em categorias médicas: uma cardiopatia, uma nefropatia... Situações que levam o indivíduo a dizer: sou cardíaco, sou renal, sou diabético. ${ }^{28}$

27 Estou me referindo à complexa sociedade urbana ocidental da atualidade. Considerações acerca de outras sociedades não são pertinentes neste estudo e exigiriam uma investigação dentro de outros moldes.

28 A língua portuguesa se presta a esta distinção. Todavia, em outros idiomas, não há demarcação lingüística tão nítida entre ser e estar. 
Este é o cartão de apresentação, ainda que nem sempre haja um entendimento preciso do sentido e da implicação dos termos pronunciados. A constatação "sou doente" está de tal forma incorporada à existência como uma essência de si, que muitas vezes se verifica uma dissociação entre a doença, na medida em que o indivíduo se percebe como sujeito-da-doença, e o tratamento imposto de fora, conforme aparece em depoimentos: "Imagine você, além de ter de fazer esse tratamento, não tenho um rim!" (sic). Neste sentido, o tratamento parece se referir a algo que não diz diretamente respeito à pessoa.

A percepção de si próprio como sujeito-da-doença provoca uma série de mudanças para o indivíduo. Enquanto se percebe como 'homem normal', ele se sente inserido na sociedade, trabalha, produz, age. Sentir-se em boa saúde, "que é, precisamente, a saúde - [é] quando se sente mais do que normal, isto é, não apenas adaptado ao meio e às exigências, mas também normativo, capaz de seguir novas normas de vida". ${ }^{29}$

Como sujeito-da-doença, a situação se modifica. O corpo não corresponde nem responde às imposições da sociedade em que está inserido.

A constatação dessa diferença e o reconhecimento de uma impossibilidade (de produção/criação) estão, todavia, embutidas na própria situação anterior, ou seja, na condição de sujeito passível de ser sujeito-da-doença. Isto significa que a possibilidade de adoecer está sempre presente. O próprio temor é reatualizado cada vez que algum próximo adoece.

Nesse sentido, o acontecimento da doença não é imprevisível para o sujeito. Sendo percebido como um acaso - daí a forma tão comum de lamento: "por que foi acontecer logo comigo?" (sic) — o acontecimento está inscrito na condição de sujeito passível de ser sujeito-da-doença. Tanto que, freqüentemente, se observa, em seguida a esse lamento, um outro: "por que não aconteceu com fulano?" (sic). Tais desabafos parecem confirmar que a possibilidade da doença, para o sujeito, é um fato. A perplexidade contida na interrogação está referida ao próprio fato e não à sua contingência.

\section{"Sou paciente"}

Assim, ser cardíaco, ser renal, em suma, ser doente envolve uma série de consequiências que, pertinentes ou não, remetem a uma situação de marginalidade, de diferença.

29 CANGUILHEM G., O normal e o patológico. Rio de Janeiro, Forense-Universitária, 1982, p. 161. 
Do ponto de vista do sujeito, a ocorrência de uma disfunção cria uma situação de desequilíbrio, no sentido de que o torna inepto para dar prosseguimento às suas atividades. Quando a disfunção se refere a uma modificação orgânica, a inadequação se vê reproduzida no próprio corpo e o indivíduo passa a se perceber impossibilitado de manter uma homeostase com seus próprios recursos. Apelando para o saber médico, o que era vivido como uma interrogação quanto à sua própria possibilidade de ação passa a ser designado, nomeado e tratado pelo médico, levando o indivíduo a se colocar sob sua tutela.

A questão da tutela configurada nessa relação (pois estar inepto requer tratamento) e que deve ser pensada também de modo inverso (pois tratamento requer estar inepto) pode ser detectada em vários outros contextos, como, por exemplo, na demanda de psicoterapia. Nas palavras de Costa: ${ }^{30}$ "No presente momento tornou-se banal constatar que a família vai mal"31 e que sem uma ajuda competente "não encontraria saída para os conflitos em que se debate". ${ }^{32}$ Neste contexto, uma série de práticas "revezam-se na tarefa de assistência às famílias desequilibradas". ${ }^{33}$ A questão, segundo o autor, não é de negar o mal-estar da família, mas discutir se os remédios propostos, ao invés de sanaram o mal, não irão perpetuar a doença". ${ }^{34}$ Ao que parece, estas práticas terapêuticas que assistem à família, colocando-a sob tutela, visam, em última análise, ao maior controle sobre ela.

Assim, a tutela dá assistência (cuidados, exames, prescrições, requisições de exames) e cobra obediência (normas a serem seguidas, remédios a serem tomados). Mas, afinal, o sujeito é socializado numa cultura em que a obediência é dada como "natural", onde há "a divisão da sociedade entre os que mandam e os que obedecem". ${ }^{35}$ o discurso médico tem a prerrogativa de reforçar esta obediência. O que a tutela médica reedita não e "o consentimento à dominação - pois seria supô-la já estabelecida - mas a obstinada vontade de produzila". ${ }^{36}$ Não se trata de uma obediência qualquer, irreverente, mas sim integralmente assumidae, como tal, requerendo uma participação sui generis, visto que

30 COSTA J.F., Ordem médica e norma familiar, op. cit.

31 Idem, p.11.

32 CLASTRES P., "Liberdade, mau encontro, inominável", in LA BOETIE E. Discurso da servidão voluntária. São Paulo, Brasiliense, 1982.

33 LEFORT C., "O nome de um", in LA BOETIE E., Discurso da servidão voluntária, op. cit.

34 Idem, p.17, grifos meus.

35 CLASTRES P., "Liberdade, mau encontro, inominável", in LA BOETIE E. Discurso da servidão voluntária, op. cit.

36 LEFORT C., “O nome de um", in LA BOETIE E., Discurso da servidão voluntária, op. cit. 
implica uma espera puciente dos resultados do tratamento que precisa seguir, das inovações médicas, das descobertas que hão de vir.

Vítima de um saber que, em nome da verdade, pode se dizer até ineficaz para curar, mas que torna difícil qualquer tentativa de rebeldia - sob pena de morte, o doente se transforma em paciente, sob todos os pontos de vista, inclusive o seu.

\section{RESUMO}

\section{A Percepção de Si como Sujeito-da-Doença}

Este artigo tem como objetivo retomar a análise de Michel Foucault sobre os tipos de poder que tornam os seres humanos sujeitos, para pensar a questão de como o sujeito se percebe a si próprio como passível de ser um sujeito-dadoença. O corpo sujeitado pela doença expressa concretamente como se estabelece uma relação de poder. Procurando analisar essa configuração, tento caracterizar, em primeiro lugar, as condições externas para a percepção de si como sujeito e, em seguida, a articulação interna, ou seja, como o próprio sujeito se vê. As raízes sociais da percepção de si como sujeito remetem aos diversos discursos sobre/do sujeito, que correspondem a estratégias de determinados sistemas (religioso, da medicina e outros). Todavia, do ponto de vista do sujeito, a condição para uma percepção de si como passível de ser sujeito-da-doença está presente na medida em que se vê, de um lado, cuidado pelo Estado e, de outro, cuidando de si. A partir daí, procuro mostrar como decorre o "tornar-se doente", termo genérico que abrange três formas seqüenciais: "estou doente", "sou doente", "sou paciente".

\section{ABSTRACT}

\section{Perceiving Oneself as a Subject-of-Sickness}

Using Michel Foucault's analysis of the types of power that make human beings subjects, the article considers the question of how a subject perceives himself as susceptible to being a subject-of-sickness. The body made into subject by sickness is a concrete expression of how a relation of power is established. In analyzing this configuration, the text characterizes both the external conditions for self-perception as subject as well as the internal conditions, that is, how the subject sees himself. The social roots of self-perception 
as a subject lead to different discourses about and by the subject, which correspond to the strategies of particular systems (religious, medicine, and others). However, from the subject's point of view, the conditions are laid for perceiving oneself as a subject susceptible to being a subject-of-sickness, insofar as the subject sees himself, on the one hand, as being cared for by the State and, on the other, as caring for himself. From this point the text endeavors to show how 'becoming sick' (a generic term that encompasses three sequential forms: 'I am sick' [estou doente]; 'I am a sick person' [sou doente]; 'I am a patient' [sou paciente]) transpires.

\section{RESUME}

\section{La Perception de Soi comme Sujet-de-la-Maladie}

Cet article a pour but de récupérer l' analyse que Michel Foucault fait des types de pouvoir qui transforment le êtres humains en sujets. L'auteur veut par là permettre une réflexion sur la question suivante: comment le sujet se perçoit-il en tant qu'être passible de devenir un sujet-de-la-maladie. Le corps assujéti par la maladie exprime concrètement la façon dont s'établit une relation de pouvoir. L'auteur s'efforce d'analyser cette configuration en essayant de caractériser, dans un premier temps, les conditions externes qui permettent qu'on se perçoive en tant que sujet et, dans un deuxième temps, l'articulation interne, c'est à dire la manière dont le sujet se voit lui-même. Les racines sociales de la perception de soi en tant que sujet nous renvoient aux différents discours sur/du sujet qui correspondent aux stratégies de certains systèmes sociaux (religieux, médical, etc...). Toutefois, du point de vue du sujet, la condition nécessaire à ce qu'il se perçoive comme passible de devenir sujet-demaladie se trouve présente dans la mesure où il constate, d'un côté, que l'Etat le soigne et, de l'autre, que lui-même se soigne. A partir de là, l'auteur s'efforce de montrer comment se manifeste ce phénomène: “tomber malade". Il s'agit en effet là d'un terme générique qui englobe trois situations qui s'enchainent: "être malade", "être un malade" et "être un patient". 
PHYSIS

\section{A PUBLIC HEALTH JOURNAL}

Issue $\mathrm{n}^{\circ} 2$ : Representation in Public Health

Introduction: Interpretation and Representation in Public Health JOEL BIRMAN

The Concept of Social Representation and Its Utility

in the Health-Care Field

Claudine Herzlich

Gender Relations, Possession, and Sexuality

PatrfCia Birman

"Libertarian Individualism" in the Social Imagery of the Sixties TANIA SALEM

Psychologism and Social Change

TÂNIA CoElho dos Santos

Becoming a Body Therapist: Social History as a Process of "Self-Construction"

JANE A. Russo

Subject, Singularity, and Interpretation in Psychoanalysis JOEL BIRMAN

Perceiving Oneself as a Subject-of-Sickness

REgINa HeRzog 


\section{ARTIGOS A SEREM PUBLICADOS NOS PRÓXIMOS NÚMEROS:}

1. A Construção Histórica do Homossexualismo no Século.XIX Jurandir Freire Costa

2. Sexualidade e Reprodução Maria ANDrÉa Loyola

3. Estado, Movimentos Sociais e Reformas na América Latina: uma Reflexão sobre a Crise Contemporânea

Cristina Possas

4. Os Encargos da Morte Claudine Herzlich

5. Os Caminhos da Mudança:

A Desinstitucionalização da Assistência Psiquiátrica Pública MAURícto LoUgon

6. Do Alienismo d "Nova Psiquiatria": Rupturas e Continuidades Ana Teresa A. Venancio

7. Homossexualidade, Bissexualidade e HIV/AIDS no Brasil. Uma Bibliografia Anotada das Ciências Sociais e Afins Carmen Dora Gutmarães

VERIANO TERTO JR.

RICHARD GUY PARKER 